\title{
O Patrimônio histórico: objeto de pesquisa do historiador
}

\section{Ricardo de Aguiar Pacheco*}

ricardo.pacheco@ufrpe.br

\section{Resumo}

Este artigo transcreve uma comunicação oral sobre as possibilidades de interpretação do patrimônio cultural no campo da história. Apresenta, rapidamente, como o tema foi percebido pela historiografia e aponta linhas de pesquisa histórica que abordam o patrimônio histórico como campo de disputa simbólica, como estratégia de construção de narrativas sobre o passado e como processo de significação dos objetos. Desejamos, pois, evidenciar caminhos pelos quais é possível desenvolver pesquisas históricas sobre o patrimônio histórico.

\section{Palavras-chave}

Patrimônio cultural; Memória social; Pesquisa histórica

\section{Historical Heritage: a research object of the historian}

\begin{abstract}
This article describes an oral communication about the possibilities of interpretation of cultural heritage in the field of history. Features, quickly, as the topic was perceived by historiography. Points as lines of historical research for the historical heritage the symbolic dispute, the strategies of constructing narratives about the past and the processes of signification of objects.
\end{abstract}

\section{Keywords}

Cultural heritage; Social memory; Historical research 
Transitar por cidades históricas como Olinda e Recife, onde vivemos, é um convite a pensarmos no patrimônio histórico. Cotidianamente, mantemos contato com as ruas, edificações e paisagens que participaram de momentos significativos do processo histórico das comunidades local, regional e nacional. Mantemos essa familiaridade com a Rua da Aurora, com o desfile do Galo da Madrugada, com a Igreja do Alto da Sé e tantos outros vestígios do passado que tomamos como objetos do nosso presente. Andamos pela Rua da Aurora observando o rio e imaginando as barcas que ali passam há séculos. Vamos brincar carnaval no imenso desfile do Galo da Madrugada como se ele ainda fosse um bloco familiar. Também fazemos aquela visita ao Alto da Sé só para contemplar as cidades se espalhando pela planície. Inseridos em nosso tempo-espaço, mal nos atemos para a historicidade desses objetos. Esse cenário das cidades históricas, ou dos lugares de memória que cada cidade mantém, levam o historiador a pensar sobre as brechas do passado no presente, sobre as sobrevivências de outros tempos em nosso próprio tempo-espaço. Enfim, sobre o lugar do patrimônio cultural na produção historiográfica.

As sociedades contemporâneas vivem um momento em que as práticas de preservação e difusão da memória social são cada vez mais comuns. $\mathrm{O}$ número e a variedade dos bens tombados pelo Estado, ou simplesmente reconhecidos pelas comunidades como de valor histórico, têm crescido de forma exponencial. Contudo a produção historiográfica, o campo acadêmico da História, pouco se tem ocupado da dimensão temporal dos objetos da cultura material e imaterial. A maior parte dos escritos e publicações históricas sobre os bens patrimoniais ainda é fruto de esforço intelectual de memorialistas que, coletando informações históricas,as reúne num quadro de memória afetiva. Por isso, falar da relação da pesquisa histórica com os patrimônios culturais necessita um delineado dos traços gerais desses objetos para depois explorar as possibilidades de trabalho que o patrimônio histórico oferece ao historiador e à pesquisa histórica.

No contexto da sociedade multicultural, diferentes grupos sociais ganham, a cada dia, maior visibilidade e, com isso, maior autonomia para construir e difundir relatos sobre sua trajetória no tempo-espaço. Surgem, assim, histórias de diferentes sujeitos como, por exemplo, a História das Mulheres e a História das Crianças, dentre outras. A essas narrativas mais gerais, ladeiam as histórias de pequenos grupos sociais como as memórias do Bairro, como as biografias de personalidades locais. Atualmente, todos os grupos sociais - das torcidas organizadas às organizações políticas - sabem da importância de instituir e difundir uma memória coletiva sobre si mesmos. Conforme nos evidencia Joël Candau (2014), todos os grupos sociais do mundo contemporâneo entendem a importância de constituir uma tradição para si, de produzir uma representação sobre seu passado, uma memória que dá sustentação simbólica à sua identidade no tempo presente.

Descrevendo a trajetória do pensamento sobre os objetos do patrimônio cultural, Françoise Choay (2006) nos leva a perceber que o contexto de maximização dos nacionalismos, da primeira metade do século $\mathrm{XX}$, seguido pela fragmentação identitária, da segunda metade, potencializou a importância social da questão do patrimônio cultural. Isso fez com que o tema fosse incorporado como objeto de reflexão de diferentes campos acadêmicos.

No Brasil, o debate sobre o patrimônio histórico tomou forma ao longo da década de 1920 através das reflexões provocadas pelos intelectuais do movimento modernista, notadamente Mário de Andrade. Foi desse debate que surgiram as primeiras repartições públicas voltadas à preservação patrimonial como o IPHAN. Ao fazer uma história do IPHAN, Maria Cecília Londres 
Fonseca (1997) nos faz perceber que, uma vez históricos. O historiador pouco investiga as institucionalizada a política para a preservação do patrimônio cultural brasileiro, foram os arquitetos ladeados por juristas- que tomaram a frente na estruturação da política pública para o patrimônio. Não foi seu propósito, mas o estudo de Marcia Chuva (2009) nos leva a perceber que, no início dessa política de preservação, em meados do século XX, os historiadores estiveram à margem do processo decisório sobre a institucionalização do patrimônio. Muito embora se identifiquem alguns historiadores como consultores contratados pelo IPHAN.

De lá para cá, o tema da política patrimonial viveu muitos embates envolvendo agentes do Estado brasileiro e grupos de interesse, mas ainda assim ele seguiu como uma questão marginal para os historiadores. Apenas para exemplificar, lembremos alguns debates gerais sobre o tema. A questão central para o patrimônio sempre foi “o que preservar?”. Essa questão foi respondida, nos anos 1930, pelos arquitetos ao dizerem "as edificações excepcionais da arquitetura barroca e modernista"; e, a partir dos anos 1980, pelos antropólogos ao dizerem "os saberes e fazeres das comunidades tradicionais". Uma questão mais atual no interior do campo é "o que fazer com os bens tombados?'. A isso os turismólogos propõem a “exploração turística”. Para essas e tantas outras questões objetivas das políticas públicas para o patrimônio cultural pouco se manifestaram os historiadores.

Para os historiadores brasileiros - salvo honrosas exceções, como Ulpiano Bezerra Menezes (1994)e Francisco Régis Ramos (2004) -, os bens patrimoniais entram no discurso historiográfico como cenários e adereços que ilustram as narrativas sobre os eventos e personagens de fato relevantes. A historiografia ainda pouco reflete sobre a prática social de preservar bens

representações sobre o passado materializadas pelo patrimônio preservado e sua relação com as identidades sociais; e raramente se ocupa de investigar o que os objetos contam sobre a vida e a organização social em que estiveram inseridos. Ou seja, o historiador está habituado a fazer um uso instrumental do patrimônio histórico, mas pouco se dedica a refletir sobre a historicidade dos próprios objetos culturais elevados à categoria de patrimônio histórico.

Essa situação da pesquisa histórica tem progressivamente se alterado. Análises da produção historiográfica francesa, como a realizada por Jacque Le Goff (1996), apontam que o estudo de novos objetos pela historiografia possibilitou a emergência de novos temas, novas abordagens para os historiadores. Uma série de objetos que antes eram marginalizados ou mesmo desconsiderados pela historiografia, passam a ser olhados pelos pesquisadores. Entre esses objetos que ampliam a fronteira da pesquisa histórica se descortina o campo do patrimônio e da memória social que foram explorados por Pierre Nora (1992) na obra seminal para o campo que chamou de "Lieux de Memóire".

$\mathrm{Na}$ historiografia brasileira, a introdução dos referenciais teóricos do campo da história cultural ocorre a partir da década de 1990. Segundo comenta Sandra Jatahy Pesavento (2003), foi nesse momento que o conceito antropológico de cultura alterou o conjunto das ciências humanas e a história em particular. A ruptura da visão clássica de cultura como um saber erudito em oposição aos saberes populares e tradicionais provocou uma revolução no pensamento social, uma inversão nos sentidos da produção historiográfica. Para historiadores do século XXI, é usual utilizar o conceito de cultura para perguntar como as comunidades marginalizadas interpretaram 
determinada norma legal ou mesmo uma teoria filosófica. Hoje, é comum fazermos a História de grupos sociais que, há algumas décadas, simplesmente não existiam na historiografia, como as mulheres e as comunidades locais... Já é possível fazer a História de temas como o cotidiano e a sexualidade abordando não apenas o mundo da materialidade, mas também as representações que agentes históricos construíram para dar sentido ao real. Ou seja, a história, tal como outras disciplinas das humanidades, deixou de tratar apenas do diretamente observável e passou a investigar as representações sociais e as subjetividades construídas no campo simbólico proposto por Pierre Bourdieu (1989).

É ancorado no conceito de cultura, entendida como o conjunto de práticas e representações sociais de uma comunidade, que o patrimônio cultural emerge como objeto historiográfico. Ou seja, para além de ilustrar os textos sobre heróis e eventos, os objetos culturais passam, eles próprios, a ser objetos de reflexão historiográfica. Em outras palavras, o historiador passa a perguntar sobre a historicidade dos objetos culturais. Mas quais as problematizações feitas sobre este objeto? Quais os problemas de pesquisa histórica estão postos para os objetos do patrimônio de forma geral? Longe de esgotar esta discussão, gostaria de apontar três percursos de pesquisa histórica pelos quais tenho, pessoalmente, me interessado, estejam eles articulados ou isolados em cada estudo de caso.

\section{A história das políticas de preservação}

O historiador é o profissional da sociedade moderna especializado em investigar os fatos sociais em sua dimensão temporal. A historiografia está habituada a tratar do Estado, suas apropriações e ações sobre o conjunto da sociedade. Não seria uma legítima extensão dessas funções problematizar as relações sociais que o Estado e os diferentes grupos mantêm com o seu passado!? Ao discutir as estratégias utilizadas pelas sociedades para se relacionar com o tempo, François Hartog (2013) nos aponta que, ao longo da sua experiência, a humanidade já estabeleceu diferentes regimes de historicidade. A prática de eleger determinados objetos materiais e imateriais como patrimônio histórico seria, assim, mais uma estratégia, em meio a outras, de as comunidades se relacionarem com seu tempo. A seleção de objetos como patrimônio cultural é uma forma de se definir como o passado será recontado para a comunidade que o elege. Ou seja, o processo de significação de um objeto como patrimônio cultural é uma prática social que tem sua historicidade e como tal pode ser investigada por historiadores.

A percepção da historicidade dos processos de legitimação do patrimônio e da memória que ele evoca, por parte do historiador, pode evidenciar os processos históricos e os interesses sociais e políticos que levaram os agentes a atribuir determinado valor a um objeto, pode evidenciar a formação e difusão de determinada memória sobre os eventos do passado trazendo à tona os conflitos e contradições existentes nesses processos. Tomemos como exemplo os processos já finalizados de tombamento de um bem qualquer, seja ele uma igreja ou uma festa popular. Não seria possível ao historiador discutir a disputa política que levou ao seu reconhecimento como bem de caráter histórico? Quais os agentes atuaram nesse processo? Quais os interesses convergentes ou conflitantes ali se manifestaram?E perceber como essas tensões se resolveram ou se mantêm latentes no passado e no presente!?

Estudos icônicos de análise das políticas públicas como o de Maria Cecília Londres Fonseca (1997) nos mostram que as políticas públicas de preservação do patrimônio cultural se relacionam com os movimentos mais amplos do processo político dos Estados 
nacionais. $\mathrm{O}$ processo político-administrativo de transformação de certos bens em patrimônio histórico, o que chamamos de tombamento, implica atribuir-lhes um valor simbólico que originalmente não lhes pertence. Abordagens como essa desenvolvem metodologias de investigação que podem ser aplicadas a diversas outras instâncias do aparato estatal de legitimação do patrimônio. Também abrem a possibilidade de investigar a ação dos diversos grupos sociais, mais ou menos organizados, na sua ação política de disputa pela legitimação de um determinado bem cultural como detentor de proteção estatal.

Essa linha de investigação, que podemos chamar de história das políticas públicas de preservação, interessa-se por entender como os mecanismos burocráticos da estrutura estatal se apropriam, ou não, dos objetos culturais, atribuindo-lhes valor de memória ou jogando-lhes ao esquecimento. Ação estatal como essa estará sempre associada a projetos políticos mais amplos, como a afirmação de um projeto de nação, e vinculada aos interesses de grupos sociais específicos que desejam sobrepor sua representação do passado sobre os demais. Ao historiador, como pesquisador dos processos diacrônicos e sincrônicos, cabe a crítica documental que evidencie o como e o porquê determinado valor simbólico foi atribuído a certo bem patrimonial.

\section{A história da memória social}

Ao escolher um objeto como patrimônio histórico, estamos retirando-o de seu contexto original para lhe atribuir uma outra funcionalidade: a de evocar um determinado passado. O patrimônio é, portanto, um discurso de segunda ordem. Uma cadeira utilizada pelo Imperador, quando integrada a uma exposição museológica, não será utilizada como cadeira; será agora um suporte para trazer à lembrança a presença do
Imperador. Ou seja, o objeto perde sua função de uso original sendo transformado em objeto de memória, em suporte material para a produção de um imaginário social sobre as relações sociais que cercaram esse objeto no passado.

A memória é entendida como a capacidade cognitiva que cada indivíduo tem de evocar mentalmente elementos ausentes. Essa capacidade individual, segundo Maurice Halbwachs (2006), é enriquecida pela memória coletiva difundida por diferentes processos sociais a que o sujeito que lembra tem acesso.É nessa dinâmica que o patrimônio cultural se torna elemento que provoca, em cada indivíduo, a lembrança de determinada memória coletiva. Contudo esses lugares e objetos de memória não são o próprio passado, mas objetos selecionados e ordenados para produzir um efeito de real que evoque esse passado. Eles são alegorias do passado.

Ao ser reconhecida pelos indivíduos como representação legítima do seu passado, essa memória coletiva atua como elemento constituinte da identidade do sujeito que a incorpora como sua. Nesse momento, a memória individual, para além de uma lembrança de uma experiência vivida, é a lembrança de elementos simbólicos que aglutinam os membros de uma comunidade em uma mesma identidade social.

Um objeto patrimonial não funciona sozinho, ele precisa estar inserido em um quadro de memória que lhe dê sentido, necessita de uma rede de significados que the potencialize um significado particular. Ao eleger determinados bens materiais ou imateriais como pertencentes ao patrimônio cultural da comunidade, estamos selecionando os eventos com os quais desejamos compor a fala autorizada sobre o seu passado. Paul Ricouer (2007) nos lembra que, nesse processo de seleção das memórias coletivas, alguns eventos são lembrados, ao passo que outros tantos são 
esquecidos ou mesmo ocultados. Organizados e ordenados pelos códigos culturais de uma comunidade, os monumentos, os museus ou os festejos são instaurados e continuamente resignificados para articular uma representação social sobre o passado que esse grupo social deseja em cada momento do tempo presente.

Um estudo histórico sobre o fenômeno de criação de determinada memória sobre um processo histórico foi feito por José Murilo de Carvalho (1990) ao abordar os monumentos e símbolos que a geração republicana edificou para fazer lembrar seus heróis e eventos. Esse estudo revela tanto as representações do processo histórico que se pretende perpetuar como as informações do passado que se deseja ocultar. Esses elementos simbólicos, que são os bens culturais, substancialmente, revelam ao historiador como um grupo político se utilizou do passado para interferir nas lutas simbólicas do seu tempo presente.

Em estudos como este,vemos que o historiador tem condições de problematizar as representações sociais produzidas sobre o passado através dos bens patrimoniais como estratégias da disputa simbólica.Os estudos históricos sobre as disputas simbólicas pelo passado podem revelar ao historiador como cada presente entende os processos históricos lhe constitui; podem elucidar sobre os usos do passado para a constituição de identidades sociais, revelando como as identidades sociais são historicamente construídas.

\section{A história dos objetos e seus usuários}

Se a história é a ciência do homem no tempo, como aponta Marc Bloch (2002), esse homem ganha potência à medida que produz cultura, que fabrica objetos materiais e imateriais que potencializam sua ação transformadora do mundo físico e social em que está inserido. Os historiadores estão habituados a utilizar como fontes históricas os documentos escritos produzidos por instituições, e pouca atenção ainda é dada para a interpretação documental dos objetos, das coisas. Eles pouco são utilizados como fontes documentais para o entendimento das relações sociais em que estiveram inseridos. Os objetos eleitos como patrimônios culturais material e imaterial possuem uma trajetória histórica que informa sobre as relações sociais em que estiveram inseridos. Assim, a história do objeto ilumina, quando não se mistura com a história de seus usuários.

Para entender essa história dos objetos, é preciso lhes interrogar sobre questões aparentemente simplistas, como sua composição e a técnica de fabricação, sabendo que as respostas aos questionamentos nos podem informar sobre os recursos materiais que o grupo social dispunha. Como também o modo de fazer pode informar ao historiador sobre as tecnologias que aquele grupo social desenvolveu. Igualmente a sua circulação entre diferentes comunidades fala da circulação de pessoas e ideias. Da mesma forma, as modificações observáveis em objetos da mesa série, produzidos ou utilizados em diferentes períodos, longe de indicar a perda de autenticidade, podem indicar a incorporação de novos materiais, novos conhecimentos e novos usos desenvolvidos pelo grupo social que os produziu ou utilizou. Tudo isso indica os desdobramentos do processo histórico vivenciado pelo objeto e seus usuários.

De modo parecido, o estudo da historicidade do objeto cultural material e imaterial também nos permite inferir sobre as formas de uso simbólico do objeto. O estado de conservação, as marcas de uso, os acréscimos ou retiradas de partes dos objetos da cultura material indicam as formas de apropriação desse objeto material por parte das diferentes gerações, indicando como os 
sujeitos históricos de momentos distintos dele se utilizaram. É comum as edificações com valor histórico sofrerem intervenções ao longo de sua vida, como: a substituição de aberturas, o acréscimo de cômodos, a destruição de partes. Essas transformações do objeto cultural, tomadas na sua historicidade, informam-nos sobre a permanência ou a transformação das práticas sociais que se desenvolveram no interior da edificação. Autores como Gilberto Freyre (2004) utilizam a estrutura arquitetônica da Casa Grande para inferir como se estabeleciam as relações sociais no seu interior. A partir da sua localização no alto da colina, deduziu-se que as varandas eram utilizadas para controlar o trabalho no campo; da ausência de portas, intuiu-se uma falta de privacidade nas relações familiares. Para além de suas conclusões, essa obra nos permite ver a possibilidade de interrogar os objetos da cultura material para desvendar, na historicidade do objeto, a história dos homens que os utilizaram.

A história dos objetos, ao utilizar o objeto cultural como fonte histórica para a interpretação das relações sociais, pode revelar muito da historicidade dos grupos sociais. Revelar não apenas sua forma de produção material, mas também simbólica. Desvendar não apenas os usos dos objetos, mas também as necessidades concretas da comunidade que por eles foram atendidas. A história dos objetos das culturas material e imaterial, portanto, é mais um caminho para acessar a experiência humana no tempo.

\section{O patrimônio histórico e as identidades coletivas}

A identidade social, como aponta Roger Chartier (1991), é o sentimento individual de pertencimento a um determinado grupo social. Ser brasileiro ou torcedor de determinado time de futebol, implica compartilhar certas representações e práticas sociais. Significa frequentar um campo simbólico no qual elementos próprios dos grupos são positivados. O patrimônio histórico, ao atribuir o valor de memória aos objetos e articular uma representação sobre o passado, aponta para uma memória coletiva que atua na formação da identidade social do sujeito.

A política de formação das identidades, explicitamente assumida pelos Estados Nacionais da Era Moderna, utilizou-se ativamente do patrimônio histórico para afirmar as identidades nacionais. Hoje, essa mesma estratégia é utilizada por diferentes grupos sociais que buscam reconhecimento público. Para autores como Lúcia Lippi Oliveira (2008), as políticas culturais da memória partem da definição dos objetos culturais significativos para aquela comunidade de sentidos. Uma vez selecionados, esses objetos se tornam metáforas que dizem aos membros da comunidade quem é o "nós" frente aos "outros". Nesse ponto, vemos o patrimônio histórico como um instrumento didático informal que comunica aos membros da comunidade sobre o seu passado. O historiador que estiver interessado nos processos de formação das identidades, não apenas as nacionais, mas de qualquer grupo social tem, nos bens patrimoniais materiais e imateriais, tombados ou não - eleitos por esse grupo, indícios sobre os elementos identitários que unem seus membros.

Aqui, a metodologia da educação patrimonial proposta por Maria de Lourdes Parreiras Horta (1999) é uma ferramenta não apenas para o historiador, mas também para o professor de História perceber a relação identitária que os indivíduos mantêm, ou não, com os objetos culturais. Baseado nessa metodologia é possível organizar ações educativas que difundem as representações sociais associadas aos objetos culturais. Também é possível utilizá-la justamente para 
identificar quais os objetos que são reconhecidos pela comunidade de sentidos como guardiões da sua memória coletiva; quais são os objetos que atuam como formadores das identidades sociais.

Refletindo sobre a sua experiência profissional no interior de um museu, Francisco Régis Lopes Ramos (2004) formula o conceito de “objeto gerador" para descrever como as peças de museu podem ser utilizadas em ações educativas para provocar os visitantes a perceberem a historicidade da sociedade que as criou e utilizou. Nesse momento, o próprio patrimônio histórico se torna instrumento de trabalho do historiador. Ao assumir a radicalidade da sua função social - pesquisar e difundir o passado das sociedades o historiador que opera com os bens culturais, com o patrimônio histórico de um grupo social, está contribuindo para a difusão, afirmação (ou negação) de determinados valores identitários no interior dessa coletividade. As ações de educação patrimonial que visam a identificar ou significar o patrimônio histórico estão, portanto, encharcadas das questões que levantamos anteriormente. Elas estão marcadas pelo poder de atribuir o valor histórico aos objetos. Elas articulam e difundem certas representações sobre o passado e, dessa forma, ativam os elementos identitários que unem ou dispersam os membros de uma comunidade. Elas tornam evidente a historicidade dos objetos culturais e de seus usuários tornando visíveis os efeitos do tempo sobre as sociedades.

\section{O patrimônio histórico e o historiador}

Na sociedade multicultural que vivemos, o debate acerca das memórias e das identidades sociais é uma vacina para o vírus da homogeneização cultural. Por isso, defendemos que tanto o historiador-pesquisador quanto o professor de História não podem furtar-se ao debate das questões patrimoniais na sociedade em que convive. A relação dos historiadores com o patrimônio histórico é por demais complexa para ser resumida por uma única fala como aqui se fez. O que tentei demonstrar brevemente é que, para além do uso instrumental do patrimônio, o historiador pode problematizar o próprio patrimônio como objeto historicamente construído. Que os objetos culturais materiais e imateriais podem ser utilizados como matéria-prima do historiador para dar o efeito de real a sua própria representação sobre o passado.

Entendemos, sinteticamente, o Patrimônio Cultural - e a Memória Social que nele se espelha como o conjunto de artefatos materiais e práticas imateriais que são selecionados por determinada comunidade ou grupos sociais com o objetivo de representar sua identidade coletiva. Os estudos históricos desses objetos podem focá-lo em diferentes perspectivas temporais. A mais evidente é a percepção das políticas culturais oficiais que trataram desses objetos e que têm como principais ferramentas jurídicas o tombamento dos bens materiais e do registro cultural dos bens imateriais. Contudo, tal ação estatal não é mais significativa que as inúmeras iniciativas de diferentes comunidades que elegem determinadas práticas sociais e seus suportes como objetos representativos da sua identidade. Trata-se, portanto, de fazer a história dos processos de reconhecimento social de determinado objeto como patrimônio cultural de determinada comunidade.

Uma segunda abordagem dos estudos históricos sobre o patrimônio pode problematizar as representações sociais produzidas a partir dos objetos considerados como patrimônio cultural daquela comunidade de sentidos. A operação de seleção dos elementos significativos que representam grupos sociais pode ser percebida de variadas maneiras que no interior das comunidades. Podem construir e consolidar 
uma representação social sobre seu passado; uma dada memória coletiva. De igual modo, podem ilustrar as transformações sofridas pela memória coletiva através das gerações que se utilizaram desses objetos culturais. Aqui não se trata de verificar a veracidade documental dos fatos lembrados, mas o impacto dessa representação do real na concretude da dinâmica social. Trata-se de identificar que versão do passado um grupo social desejou consolidar em seu tempo presente. O que podemos chamar de uma história da memória social.

Os estudos históricos sobre o patrimônio histórico também podem focar a trajetória do próprio objeto como estratégia para perceber características da vida material e simbólica das comunidades. Tal como as fontes documentais escritas ou iconográficas, também os objetos, quando interrogados pela crítica documental, informam ao historiador sobre as relações sociais em que esteve inserido. Trata-se de entender que o patrimônio cultural imaterial são práticas sociais que se utilizam de suportes materiais. Que o patrimônio cultural material é suporte para o desenvolvimento de práticas. Juntos, práticas e suportes, constituem uma unidade cultural. Essa história dos objetos ajuda o historiador a reconstruir determinadas dimensões da vida social do passado inacessíveis por outros meios. Evidência-nos as soluções tecnológicas, os valores culturais e as limitações técnicas com as quais os grupos sociais conviveram, ou transformaram, em diferentes momentos e processos históricos.

O estudo histórico dos objetos do patrimônio cultural material e imaterial é, portanto, uma temática que precisa ser observada pelos historiadores com mais atenção. Praticamente todos os temas de pesquisa histórica baseados em documentação escrita podem encontrar reforço com a observação e análise de objetos culturais materiais ou imateriais que os cercam. Perceber essa potencialidade implica aprimorar as ferramentas teóricas e metodológicas para essa análise. Tarefa para uma nova geração de historiadores. 


\section{Referências}

Bloch, Marc. Apologia da História, ou, O ofício do historiador. Rio de Janeiro: Zahar, 2002.

Bourdeiu, Pierre. O poder simbólico. São Paulo : Difel, 1989.

Candau, Joël. Memória e identidade. Vol. 2014. São Paulo: Contexto, 2014.

Carvalho, José Murilo de. A formação das almas. São Paulo: Companhia das Letras, 1990.

Chartier, Roger. “O mundo como representação.” Estudos Avançados, 1991: 173-191.

Choay, Françoise. A alegoria do patrimônio. São Paulo: Estação Liberdade, UNESP, 2006.

Chuva, Marcia. Os arquitetos da memória: sociogênese das práticas de preservação do patrimônio cultural no Brasil (anos 1930-1940). Rio de Janeiro: UFRJ, 2009.

Fonseca, Maria Cecília Londres. O patrimônio em processo: trajetória da política federal de preservação no Brasil. Rio de Janeiro: Editora UFRJ, 1997.

Freyre, Gilberto. Casa Grande \& Senzala. São Paulo : Global, 2004.

Halbwachs, Maurice. A memória coletiva. São Paulo : Centauro, 2006.

Hartog, François. Regimes de historicidade: presentismo e experiência do tempo. Belo Horizonte: Autêntica Editora, 2013.

Horta, Maria de Lourdes Parreiras, Evelina Grunberg, e Adriane Queiroz Monteiro. Guia básico de educação patrimonial. Rio de Janeiro: IPHAN, 1999.

Le Goff, Jacques. História e memória. Campinas, SP: Unicamp, 1996.

Menezes, Ulpiano Bezerra. "Do teatro da memória ao laboratório de história: a exposição museológica e o conhecimento histórico." Anais do Museu Paulista 2 (1994): 9-42.

Nora, Pierre. Les lieux de mémoire. Paris: Gallimard, 1992.

Oliveira, Lucia Lippi de. Cultura é patrimônio: um guia. Rio de Janeiro: FGV Editora, 2008.

Pesavento, Sandra Jatahy. História \& história cultural. Belo Horizonte: Autêntica, 2003.

Poulot, Dominique. Uma história do patrimônio no ocidente, séculos XVIII-XXI: do monumento aos valores. São Paulo: Estação Liberdade, 2009.

Ramos, Francisco Régis Lopes. A danação do objeto: o museu no ensino de história. Chapecó: Argos, 2004.

Riocuer, Paul. A memória, a história, o esquecimento. Campinas: Editora da UNICAMP, 2007.

Submissão: 06/05/2017

Aceite: 06/08/2017 